\title{
ANNALS
}

OF

\section{The Entomological Society of America}

\section{THE EVOLUTION OF THE WEBS OF SPIDERS.}

By J. H. Comstock, Cornell University.

\section{ABSTRACT.*}

The making of its wonderfully regular web by an orb-weaving spider is a remarkable instance of specialization in habits; and correlated with this are equally remarkable specializations of structure. In the construction of their webs some spiders use several distinct kinds of silk, to produce which several distinct sets of silk glands have been evolved; and to manipulate this silk elaborate spinning organs have been developed.

The tracing of the steps by which these specializations have been evolved must be, in the present state of our knowledge, largely conjectural. We are forced to follow the method commonly employed in constructing genealogical trees. We will look for generalized conditions and from these attempt to trace the evolution of those more specialized.

A very little study by this method is sufficient to show that the web-making habit has not progressed in a single direct line. Beginning with the simplest type of web, we find that this type has been modified in widely different ways in the different families of spiders.

In our search for a starting point we gain no help from a study of other arachnids than spiders. Silk organs are of rare occurrence in the other orders of the Arachnida. It is said that the tailless whip-scorpions carry their eggs in a sac formed of a dark brown transparent material containing some threads; but the source of this material has not been described. It is well-known that the Pseudoscorpions spin silk; but the silk glands of these

* This address, delivered at the annual meeting in Washington, D. C., Dec. 27, 1911, was illustrated by lantern slides made from photographs of the webs described. These photographs are reproduced in a volume on the Arachnida of North America, "The Spider Book," by J. H. Comstock, now in press. 
creatures are in the cephalothorax and open through the tips of one pair of jaws, the cheliceræ, while the silk glands of spiders are in the abdomen and open through specialized legs at the opposite end of the body. Any genetic connection that there may be between these two sets of silk organs is too remote to throw any light on the particular problem before us. It is evident that in our study of the evolution of spider webs we are forced to confine our attention to the habits of spiders.

It is probable that the production of silk by spiders was not primarily evolved for the making of webs for capturing prey. The representatives of many families do not spin webs; and there is no reason to believe that these non-web-making families have descended from web-making forms. It seems more probable that the use of silk for making webs for capturing prey is a secondary or tertiary adaptation.

All spiders use silk in caring for their eggs. And it seems probable that this was the primary use of silk in this group of animals.

With some spiders, as Pholcus, only a little silk is used for this purpose, merely enough to fasten the eggs together in a ball; with some spiders the habit of making an elaborate egg-sac has been evolved; and many types of these egg-sacs exist. A single illustration of an elaborate egg-sac is sufficient for our present purpose. Glyptocranium cornigerum makes an egg-sac, with a vase-shaped outer covering, and fastens it to a twig with bands of silk in a manner which almost suggests human intelligence.

Spiders having acquired silk for the protection of their eggs have utilized it for other purposes, of which the making of webs for capturing prey is but one, and probably not the next one in the sequence of the different uses of this substance.

Many spiders that live in burrows in the ground strengthen the walls of their burrows by a lining of silk. Some of these, the well-known trap-door-spiders close the entrance to their nest by an elaborately constructed lid; and some build a turret over the entrance of their burrow. In the case of the turret spiders we have, I believe, from observations made on one that I kept in confinement in my office for several months, species that build a structure to facilitate the capturing of their prey, the turret serving as a watch tower from which insects invading the region near the nest can be more easily seen. 
A much more elaborate provision for capturing prey made by a burrowing spider by prolonging the lining of its tube is the purse-web of Atypus.

Another remarkable device to aid in the capture of prey is made by one of the Dysderidæ, the species known as Ariadna bicolor. This spider lives in a silken tube built in the hole that serves as a retreat for the spider. This tube is suspended from a frame-work of threads, built at the entrance of the retreat, in such a way that any disturbance of the exposed parts of the nest is communicated to the occupant of the tube. From the frame-work at the entrance of the retreat there extends a series of radiating lines each of which passes over two or more piers which keep it suspended a short distance from the face of the supporting object; so that any insect walking on this object is sure to disturb one of these lines. The touching of one of the trap lines by an insect results like the touching of the spring of a "Jack-in-the-box." The spider comes forth with amazing swiftness, seizes the unlucky insect, and retreats with it instantly to its lair.

Let us pass now from this glance at unusual devices for the capture of prey to a study of the more common forms of spider webs.

How did the web-making habit arise? What were the steps by which the gap between the use of silk for the protection of eggs to its use in the construction of an elaborate web for the trapping of prey was bridged? With our present knowledge our answer can be only an hypothesis.

The most important step I believe to have been the acquiring of the habit of spinning a drag-line, the thread which most spiders spin wherever they go. The first drag-line may have been a thread which a spider was using in the construction of an egg-sac and by which the spider found it could drop from an elevated position to a lower one; from this all of the well-known uses of the drag-line could be evolved.

The complete history of the development of this activity is not so simple, however, as this statement might indicate. For there has been evolved a special kind of silk for use as a dragline which differs in structure from that used in making egg-sacs and which is secreted by a distinct set of glands. But this is only one of several differentiations that have arisen; for now at 
least seven different kinds of silk, each adapted to a special purpose, are spun by spiders.

The step from a drag-line to a web is not a great one. A spider spinning a thread wherever it goes would make a web if by chance it moved about in a limited space as in some nook in which it had taken up its abode. In such a web insects would be trapped, and thus might arise the habit of building webs for the purpose of trapping insects. The simpler webs made by spiders are irregular nets formed of the same kind of silk as that of which the drag-line is made. Such a web is made by Pholcus. It consists of a comparatively few threads spun without any regularity of arrangement.

A marked step in advance of the irregular nets of Pholcus is illustrated by the regular webs of the sheet-web-weavers, the Linyphiidæ. These are constructed of dry silk, the kind used for the drag-line, but they are of more or less definite form. That of Linyphia phrygiana is a flat sheet spun between the twigs of a shrub or a tree. Linyphia pusilla makes a horizontal platform between stems of grass and spins an irregular net above it to impede the flight of insects and cause them to fall upon the platform where they can be caught by the waiting spider. Linyphia marginata makes a filmy dome beneath which it waits to capture the insects that fall upon it after striking in their flight the irregular net spun above the dome, and Linyphia communis spins a bowl-shaped web with an irregular net above and a sheet below it.

A type of web resembling those of the Linyphiidæ in consisting largely of a sheet of silk, but differing in having a funnelshaped retreat is made by certain members of the Agelenidæ of which the grass-spider, Agelena naevia is our most familiar example. A similar web is made in the basement of buildings and in other secluded places by Tegenaria.

All of these webs of which illustrations have been shown so far are made of the same kind of silk as that used for the drag-line. Their function is to impede the flight of insects giving the waiting spider time to capture them.

In the course of the evolution of the web-building habit there has been developed in many families of spiders organs for producing a second kind of silk, which being of a viscid nature is fitted to hold fast the entangled insect. The nature of this 
viscid silk differs greatly in the different families producing it; and several types of it will be discussed before I close.

Among the spiders that spin a simple web are the members of the Theridiidæ of which the common domestic spider, Theridion tepidariorum, is a familiar example. The webs of this spider abound in the corners of neglected rooms, and are nearly as simple as those of Pholcus. They probably represent a slight elaboration of the primitive type.

In the family Theridiidæ is found the simplest form of viscid silk, this is merely a viscid liquid which is flung over the entangled prey. But although the silk itself is simple, correlated with its production there has been developed a specialized organ fitted for flinging the silk. This consists of a comb on the tarsus of the fourth legs.

The presence of this comb is a distinctive family characteristic. And the silk is produced by a set of glands, the lobed silk-glands, which have been found only in this family. The Theridiidæ, therefore, judged by their biological features and the correlated anatomical structures represent the tip of a distinct line of specialization.

In the other families of spiders that make use of viscid silk, there is produced a thread or a band that is viscid, and which forms a part of the web.

The webs in the construction of which two kinds of silk are used vary greatly in complexity of structure; and in different families the direction of specialization has been very different.

Two quite different lines of specialization can be recognized. In one group of families the foundation of the web, the part made of dry silk, is comparatively generalized in structure, while there has been evolved a highly specialized band for supporting the viscid silk. In another group of families the foundation of the web is very regular in form, that is to say, highly specialized, while the structure of the viscid silk has remained comparatively simple.

The first of these two lines of specialization, that in which the foundation of the web remains simple while the viscid silk becomes complex is found in a group of families known as the Cribellatæ. These are so called because they possess in addition to the silk glands possessed by other spiders a large number of small silk glands which open through a sieve-like plate, the cribellum, situated in front of the spinnerets. These glands 
are supposed to secrete the viscid silk. Correlated with the presence of a cribellum is the presence of a comb of bristles on the metatarsus of the hind legs for manipulating this silk.

It should be noted in this connection that viscid silk is produced by at least three different sets of glands in different families of spiders. By the lobed glands in the Theridiidæ, as already described; by the cribellum glands in the Cribellatæ; and in the orb-weavers to be described later it is obviously produced by some other glands, as these spiders possess neither the lobed glands nor the cribellum glands. Apparently this very useful product has arisen independently at least three times within the order Araneida.

The viscid silk of the Cribellatæ is a band-like structure whose form is partly determined by the combing action of the calamistrum. I have, therefore, termed it the hackled band.

The hackled band of one of the Dictynidæ, that of A maurobius may be taken as an example. This band consists of two parts; first, a supporting structure, which may be termed the warp; and second the viscid silk, which may be termed the woof.

The warp consists of four elastic threads, two of which are straight and two are curled. The woof is a narrow sheet of viscid silk, the edges of which are undulating. It is probable that each undulation was produced by a stroke of the cribellum.

While it is probable that the viscid silk, is spun from the cribellum glands, the threads constituting the warp are doubtless spun from spinning tubes situated on the spinnerets.

Turning to the webs of the spiders that spin a hackled band, we find great differences in the extent to which this band is used and also in the nature of the web of which it forms a part. It is easy to arrange these webs in a series which suggests a possible course of their evolution.

In the Dictynidæ is to be found the simpler types in this series. Here the foundation of the web is irregular, its form depending very largely upon the situation in which it is built. The following will serve as examples:

Dictyna foliacea spins an irregular web of dry silk across the concavity of a leaf; and mingled with the dry threads are strands of viscid silk that have no regularity of arrangement.

Dictyna volucripes spins an irregular web of dry silk upon the stems of herbaceous plants; and upon this foundation stretches its hackled band in comparatively regular ladder-like 
frets. In the webs of this species, the larger part of the web is made of dry silk. While the hackled band is doubtless the most efficient factor in the capture of insects, it is still a subordinate part of the web.

In the webs of Dictyna sublata the utilization of the hackled band is carried much farther. Here only so much dry silk is used as is necessary to support an elaborate lace-like sheet of viscid silk. This represents the quantitative extreme in the use of viscid silk.

A somewhat similar condition exists in the webs of a species of Amaurobius which spins its webs on cliffs.

In the webs of Hypochilus thorellii is found the same type of hackled band as in the webs of the Dictynidæ. I have been able to find no differences between the hackled bands of this spider and that of Amaurobius. But the web of Hypochilus is of regular form being lamp-shade shaped.

It is a remarkable fact that this spider which has retained the most generalized condition of its respiratory organs of all true spiders, being four lunged like the Tarantulas, should have attained the making of a regular web.

While the hackled bands of Amaurobius and Hypochilus are remarkable structures they lack much of representing the extreme of specialization in this direction. To see this we must examine the web of Filistata, a very common house spider in the South. Here the hackled band is composed of four distinct kinds of silk. But the web itself is more simple than that of Hypochilus.

Let us turn our attention now to the second of the principal lines of specialization of webs, that in which the attention of the spiders, to speak figuratively, has been devoted to perfecting the foundation of the web, while the viscid silk has remained comparatively simple. The culmination of this line is reached in the webs of the orb-weaving spiders.

There are two families of orb-weaving spiders, the Uloboridæ and the Argiopidæ. In the more typical webs of each of these families the most striking feature is the presence of a central, more or less orbicular part in which the frame-work of the web consists of radiating lines, which in the completed web support the viscid silk. The regular spacing of these radii gives the maximum of stability to the web with the minimum use of material. Most of the webs already described are built against 
firm supports. The orb-weavers stretch their webs in mid-air between distant supports. Webs so exposed must be replaced frequently in part at least. It is important therefore that there should be an economical use of the dry silk.

It is only the orbicular part of the web that is renewed at frequent intervals. The outer foundation lines are a permanent investment and are carefully saved.

In the two families of orb-weavers the same type of foundation has been attained. The web of Uloborus, so far as its foundation is concerned, closely resembles an argiopid web; but the nature of the viscid silk is very different. The Uloborids possess a cribellum and calamistrum and spin a true hackled band. This, however, is of a comparatively generalized type, the warp consisting of only two straight, elastic threads. The viscid silk is evidently less fluid than that of other families and consequently retains the form given it by the combing strokes of the calamistrum, that is a regular series of overlapping lobes.

A remarkable variation of the uloborid type of web is the triangular web of Hyptiotes, which consists of only a sector of a web.

Passing to the webs of the Argiopidæ, we find in the different subfamilies striking variations in the details of the structure of the orb, only a few of which can be mentioned here. But first let us examine the viscid thread.

In these webs where is found the most highly specialized frame-work of dry silk, there is found the simplest type of viscid thread. This consists of a double thread of elastic silk, upon which is poured the viscid silk. This viscid silk, is fluid, and almost immediately the surface tension of this fluid causes it to collect in drops, which are distributed along the elastic support in a very regular manner.

The simplest known orb-web is that of Theridiosoma, one of the Argiopidæ. This has few radii and no hub; it is used, however, in a peculiar way, described long ago by Dr. McCook.

Before examining more perfect argiopid webs, I wish to review briefly the steps in the building of an orb-web. These are so well-known that it is only necessary to enumerate them without a detailed description. First the outer frame-work is made; this is a permanent part of the web. In the open space surrounded by this frame-work the radii are then stretched. Upon the radii in the vicinity of the point where they converge 
is built the hub of the web, the nature of which varies greatly in the webs of different divisions of the family. Extending from the hub a spiral line is spun upon the radii the turns of which are a considerable distance apart. As the function of this line is merely to hold the radii in place during the later stages of the web building, I have designated it the spiral guy line. This, like all portions of the web made up to this point is composed of dry silk. After the radii have been firmly stayed by the spiral guy line, the spider beginning at the outer edge of the orb and adds the loops and turns of the viscid line, destroying the spiral guy line as it progresses.

Frequently the remains of the spiral guy line can be seen as a series of regularly spaced dots on the radii of completed webs.

Great differences exist in the different webs of orb-weavers as to the relative amount of dry and viscid silk, one extreme is illustrated by the web of Metepeira; the other, by the web of Cyclosa.

In the webs of most orb-weavers, the entire orb is replaced frequently, only the outer foundation lines being a permanent investment. The spiral guy line is destroyed during the building of the web, the radii and viscid line are sacrificed when it is necessary to renew the orb.

But in the webs of Nephila we find that the web is so constructed that it is only necessary to renew the viscid line as it becomes injured or dry.

Here is attained the extreme of economy in the use of the dry silk, although the first investment is somewhat greater than in ordinary orb-webs. The orbicular part of an ordinary orb-web may be compared to a shack built for a day; the orb of Nephila, to a permanent structure built to stand during the life time of the occupant.

This difference is brought about by radical differences in the style of architecture. In the orb of Nephila the radii are forked, which results in the outer part of the orb being as firm as the central portion. The spiral guy line is attached to each radius lengthwise for a short distance; as this guy line is pulled taut it draws the radius out of its direct course; the course of each radius is, therefore, zigzag. The viscid line is looped back and forth between the turns of the guy line, and gives the web a banded appearance. When the web is repaired only the 
old viscid line is removed, the radii and the guy line remaining intact.

An old female Nephila which I watched for a number of days at Miami, Florida, carried her economy in the use of silk a step farther. This individual removed the viscid thread of only one half of the web each night, repairing alternate halves on alternate nights.

During the period that this spider was under observation there was a very severe storm, five inches of rain falling in the course of a few hours. When the web was visited on the following morning it was found that it had been repaired throughout.

The steps in the perfecting of the webs of spiders briefly sketched in the preceding pages can be indicated in a tabular form as follows:

WEBS OF SPIDERS.

A. Webs made by spiders that use only dry silk.

B. Irregular webs

Pholcidæ

BB. Regular webs.

C. The sheet webs

Linyphiidæ

CC. The funnel-webs

Agelenidæ

AA. Webs made by spiders that use both dry and viscid silk.

B. Webs consisting only of dry silk; the viscid silk being flung upon the prey.

Theridiidæ

BB. Webs consisting of both dry and viscid silk.

C. Webs consisting of a comparatively generalized foundation of dry silk and a highly specialized band supporting the viscid silk.

D. Warp of hackled band consisting of two straight and two curled threads.

E. Foundation of web irregular

EE. Foundation of web regular.

DD. Warp of hackled band consisting of four curled threads and a supporting cord.

CC. Webs consisting of a highly specialized foundation and a comparatively generalized viscid thread or band.

D. Webs containing a hackled band............ Uloboridæ

DD. Viscid silk not hackled ................ Argiopidæ

E. Radii and spiral guy line temporary

Most orb-weavers

EE. Radii and spiral guy line permanent..... Nephila 


\section{$2 \mathrm{BHL}$ Biodiversity Heritage Library}

Comstock, John Henry. 1912. "The Evolution of the Webs of Spiders." Annals of the Entomological Society of America 5, 1-10. https://doi.org/10.1093/aesa/5.1.1

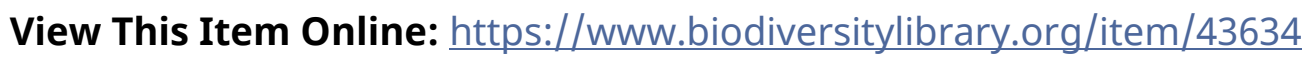

DOI: https://doi.org/10.1093/aesa/5.1.1

Permalink: https://www.biodiversitylibrary.org/partpdf/193590

\section{Holding Institution}

Smithsonian Libraries

\section{Sponsored by}

Smithsonian

\section{Copyright \& Reuse}

Copyright Status: NOT_IN_COPYRIGHT

This document was created from content at the Biodiversity Heritage Library, the world's largest open access digital library for biodiversity literature and archives. Visit BHL at https://www.biodiversitylibrary.org. 